\title{
Are neighbours harmful or helpful in Fucus vesiculosus populations?
}

\author{
Joel C. Creed*, T. A. Norton, Joanna M. Kain (Jones) \\ Port Erin Marine Laboratory, Port Erin, Isle of Man IM9 6JA, United Kingdom
}

\begin{abstract}
In order to investigate the effect of density on Fucus vesiculosus L. at all stages of its development, 2 experiments were carried out. A culture study in the laboratory found that increased density resulted in depressed growth and a negatively skewed population structure during the first month in the lives of freshly settled germlings. Intraspecific competition acts even at this early stage, and the limiting factor was probably nutrients. 'Two-sided' ('resource depletion') competition and an early scramble phase of growth may explain negative skewness in plant sizes. On the shore experimental thinning by reduction of the canopy resulted in increased macrorecruitment (apparent density) from a bank of microscopic plants which must have been present for some time. With increased thinning more macrorecruits joined the remaining plants, making population size structures highly positively skewed. Thinning had no effect on reproduction in terms of the portion of biomass as reproductive tissue. Manipulative weeding allows an assessment of the potential spore bank in seasonally reproductive seaweeds and revealed that there are always replacement plants in reserve to compensate for canopy losses. In $F$. vesiculosus the performance of individuals early on is crucial to their subsequent survival to reproductive stage, as neighbours are generally competitively harmful. However, a failure to 'win' early on may not necessarily result in the ending of a small plant's life - the 'seed' bank still offers the individual a slim chance of survival and protects the population from harmful stochastic events.
\end{abstract}

KEY WORDS: Culture. Density Fucus vesiculosus Intraspecific competition Thinning

\section{INTRODUCTION}

Density dependence and intraspecific competition are closely linked in both plant and animal populations (Begon \& Mortimer 1986). The manipulation of density is the main tool ecologists have used to study intraspecific competition. A large body of circumstantial evidence for the likelihood of intraspecific competition in seaweed populations comes from the ultimate density manipulation, total clearance of a mature plant canopy (e.g. Rosenthal et al. 1974). However, in such experiments, changes in canopy sweeping (e.g. Westermeier \& Möller 1990), herbivory (e.g. Kirkman 1981), allelopathy (e.g. Dayton et al. 1984) and nutrient avail-

\footnotetext{
- Present address: Jardim Botannico do Rio de Janeiro, Rua
} Pacheco Leão 915, 22460-030, Rio de Janeiro - R.J., Brazil ability (e.g. Gerard \& Mann 1979) which accompany manipulations are not controlled, but even so, light stimulation is still most often cited as the reason why juveniles appear in place of a denuded canopy (e.g. Santelices \& Ojeda 1984a, b, Druehl \& Breen 1986, Robertson 1987).

Various more refined methods have been used to study the effects of density in large seaweed populations including assembling them on artificial surfaces (Hurtado-Ponce 1990), thinning natural populations (e.g. Chapman \& Goudey 1983) or using populations naturally occurring at different densities (e.g. Schiel \& Choat 1980). For studying small scale density effects, laboratory culture (Reed 1990a) or outplanting (Reed 1990b) have been used. The results of such studies have usually demonstrated density dependence and intraspecific competition in the form of reduced 
growth rates (Black 1974. Schiel 1985, Reed 1990b), greater mortality (Chapman \& Goudey 1983, Reed 1990a), reduced recruitment (Black 1974, Reed 1990b) or reduced reproductive potential (Reed 1987) in high density treatments.

Crowding may also confer advantages on monospecific seaweed populations. For instance Reed et al. (1991) found that kelp spores needed a minimum density for subsequent fertilization and sporophyte production. 'Safety-in-numbers' factors may be responsible for other reports of higher survival at higher densities in stands of small seaweeds (Schonbeck \& Norton 1978, Hruby \& Norton 1979, Hay 1981, Lubchenco 1983, Vadas et al. 1990). Other authors have found evidence of negative competition (sensu Begon \& Mortimer 1986) in larger seaweeds too (Yoshida 1972, Schiel \& Choat 1980, Schiel 1985, Ang \& De Wreede 1992). From these studies it is clear that the effects of neighbours are complex and may be beneficial or harmful to individual plants. Furthermore, these effects are dictated by the biology of the species and the physical domain which it inhabits.

The sizes of seaweed range over 5 orders of magnitude (average gametes 10 to $20 \mu \mathrm{m}$, adults $15 \mathrm{~cm}$ to $5 \mathrm{m+}$; Vadas et al. 1992), about an order of magnitude greater than trees, and because of this, data for the whole life of a population are hard to find in the literature. Particularly rare are studies which detail the first few weeks growth of seaweed propagules, a time at which life-long advantages or disadvantages may be gained if a hierarchy of exploitation of resources exists. In essence, the first week in a propagule's life may dictate its future existence and any population studies should address the early post-settlement stage.

Fucoid algae are useful. subjects for population studies as compared to most other algae they have a relatively simple life cycle, without a prolonged haploid phase (Chapman 1986). Fucus vesiculosus occurs in dense, monospecific, even-aged stands and is an important component of the intertidal flora on semiexposed shores in northern Europe. However, unlike other fucoids $[F$. distichus ssp. edentatus (de la Pyl.) Pow.: Thom 1983, Keser \& Larson 1984; F. distichus L. emend. Powell: Ang 1991, Ang \& De Wreede 1992; F. spiralis L.: Keser \& Larson 1984, Robertson 1987; Ascophyllum nodosum (L.) Le Jolis: Keser et al. 1981, Vadas et al 1982, 1990, Cousens 1985, 1986], F. vesiculosus has received little attention, and we therefore selected this species for the present study to investigate the effect of density on its population dynamics by: (1) following the development of different densities of $F$. vesiculosus during the crucial first month of growth in a laboratory study which minimised confounding factors usually found on rocky shores and (2) following the long-term development of different densities of $F$. vesiculosus created by manipulating a natural population on the shore. The aim of this investigation was to determine whether neighbours were harmful or helpful to individuals in $F$ vesiculosus populations.

\section{MATERIALS AND METHODS}

Laboratory populations. Material was collected from an area of Port St. Mary Ledges, Isle of Man, UK, in. August 1991 All the receptacles were excised from 20 female and 10 male fertile Fucus vesiculosus plants, which were then pooled by gender and spread on plastic trays to be sun-dried for $5 \mathrm{~h}$. The receptacles were then quickly washed in fresh water before being half covered with filtered sea water. After $1 \mathrm{~h}$ the water containing gametes was removed.

The water containing oogonia was passed through a $100 \mu \mathrm{m}$ filter to remove egg packets and other dross and isolate single eggs from egg clusters. The filtrate was passed through a $60 \hat{\mu} \mu$ filter which retainod oggs but allowed the mucus-thick water to pass. In order to remove smaller, slower sinking propagules of other algal species the eggs were washed with filtered sea water into a measuring cylinder which was then vigorously shaken before being left to stand. Shaking removed most epiphytes and excess mucilage. After this settlement period most of the water was decanted, sea water added, and the process repeated twice more. The water containing sperm was passed through a $40 \mu \mathrm{m}$ filter to remove dross.

Fourteen clean glass slides were laid out in the centre of each of 3 glass settlement tanks filled to a depth of $2 \mathrm{~cm}$ with filtered sea water. The egg and sperm suspensions were mixed, and aliquots taken to make 100 , 10 and $1 \%$ solutions of the original made up to $500 \mathrm{ml}$. These were decanted into the tanks in a constant temperature room for a day to allow settlement. Densities obtained were approximately 200, 20 and 2 plants $\mathrm{cm}^{-2}$

Three slides of each density were then numbered and placed (interspersed) in each of 4 tanks of filtered sea water The cultures were grown under $24 \mathrm{~h}$ light at $200 \mu \mathrm{mol}$ photons $\mathrm{m}^{-2} \mathrm{~s}^{-1}$ supplied from Thorn EMI $58 \mathrm{~W}$ Polylux 4000 light tubes at $15^{\circ} \mathrm{C}$ with water changes every $2 \mathrm{~d}$.

Using one of the spare sparsely settled slides, the number of sub-samples needed adequately to describe a slide population was assessed and found to be 12 fields of view of $5.3 \mathrm{~mm}$ diameter. In order to subsample without bias, a target slide was made which consisted of 12 random dots and which was placed under each slide to determine sample positions. 
At each sample time 3 randomly chosen experimental units (slides), one bearing each density, were taken from each of the 4 tanks. The outlines of the plants were traced using a camera lucial. In order to prevent potential bias, the drawings were made before the slide number was noted. The slides were then soaked in fresh water to remove salt, oven dried at $60^{\circ} \mathrm{C}$, dry weighed on a balance accurate to $0.0001 \mathrm{~g}$, cleaned of plants, rinsed, redried and reweighed, the difference in weights being a rough estimate of the total dry weight of plants on a slide.

The images were digitized using a Graf/Bar Mark II sonic digitizer (Science Accessories Corporation) into a PC and DesignCAD 2-D v4.2 software. Each plant was simplified to a line of maximum plant length and the images imported into a bespoke Lotus 123 macro which calculated plant lengths and various other population parameters.

Field populations. The area of shore at the Ledges, Port St. Mary, used for this experiment was already being used to monitor populations of Fucus vesiculosus. Five months earlier the $10 \times 5 \mathrm{~m}$ area consisting of a barnacle-limpet-Fucus matrix had been delineated and treated as follows: any Fucus plant $>1 \mathrm{~cm}$ tall and all other plant species present were removed. To reduce herbivory and barnacle predation visible gastropods were also removed.

In January 1991 this well-established stand was used to study the effect of artificial thinning. Sixteen $0.25 \mathrm{~m}^{2}$ areas were marked in 4 groups of 4 . Care was taken to avoid bare patches (which limpets had previously occupied), and only areas with $100 \%$ barnacle cover were included, as at this site young Fucus plants grew exclusively on barnacles. The plant size structures of these areas were similar. Per group each area was randomly assigned a thinning treatment. The aim of thinning manipulations was not only to reduce pre-existing densities by differing amounts, but also to preserve the population structure during this process. Using recently gathered population structure data to generate simple size classes, relative proportions of plants of each size were removed selectively from $100 \mathrm{~cm}^{2}$ treatment units within the marked areas. Around each area a $30 \mathrm{~cm}$ buffer zone received the same manipulation but was not sampled. Treatment was carried out over a period of $5 \mathrm{~d}$ (10 low tides), resulting in thinning of 0 , 38,63 or $88 \%$ of plants, which corresponded to final densities of approximately 4000, 2500, 1500 and 500 plants $\mathrm{m}^{-2}$.

Destructive sampling was carried out at intervals, one sample unit being taken at random from within each area of each group; but, because of damage to some areas, the total number of sample units per time was: unthinned (control), $\mathrm{n}=3$ for the first 4 sample times and $\mathrm{n}=2$ for the last 2 times; thinned areas, $\mathrm{n}=4$ for the first 4 sample times and $n=2$ for the last 2 times. The size of the sample unit was increased as the population developed ( 25 to $200 \mathrm{~cm}^{2}$ ).

The lengths of plants were measured to an accuracy of $1 \mathrm{~mm}$ and biomass, as a collective dry weight (oven dried at $60^{\circ} \mathrm{C}$ ) of all plants in each sample, was weighed with a balance. When plants became reproductive 3 additional parameters were measured: the number of receptacles on each reproductive plant, the number of reproductive plants in the population and the total dry weight of excised receptacles of the population as an estimate of reproductive potential.

Statistical analyses. To describe the populations, coefficients of variation and skewness were calculated as in Zar (1984), and Gini coefficient as in Weiner \& Solbrig (1984) taking into account recommendations of Dixon et al. (1987). The coefficient of variation is a measure of variability in plant sizes, while the skewness coefficient describes hierarchy. The Gini coefficient describes inequality of plant sizes. All 3 statistics have different properties, and their relative merits have been considered previously (Weiner \& Solbrig 1984, Bendel et al. 1989). In this study Gini and variation coefficients were highly correlated and thus only the Gini and skewness coefficients are presented. In the case of the field populations only skewness is considered as all 3 statistics were highly correlated because of substantial treatment effects.

Tests of homogeneity, ANOVA and Tukey tests were performed using Minitab Statistical Software (Minitab Inc., PA, USA). Where desirable, data were transformed to meet the assumptions of the parametric statistics. The field data presented variable replication, and the GLM model (Minitab Statistical Software) was used to perform ANOVA on these non-balanced, 'full rank' data

Laboratory and field experiments were similar, with the factors density, time and block (tank in the laboratory, group on the shore) unreplicated in a randomized factorial block design. The rationale for these experimental designs was that randomized block experiments are desirable because they reduce the possibility of chance segregation, and prevent pre-existing gradients and nondemonic intrusion from hiding or generating spurious treatment effects (Hurlbert 1984). They are also more economical. It was assumed that block = replicate and that block did not interact with other factors. All ANOVA therefore incorporated the $F^{\prime}$ or Pseudo $F$ test (Hicks 1982) to investigate interactions between block/replicate with the factors time or density. No interactions were found for any variables, the assumption that block interactions were zero was justified, and replicate:time and replicate:density terms were pooled. 


\section{RESULTS}

\section{Laboratory populations}

Important differences in the development of population structure of the 3 densities occurred (Fig. 1). After 5 d negative skewness was highest in low density populations because $70 \%$ of plants were 0.2 to $0.4 \mathrm{~mm}$ in length, while the highest density populations were essentially normal, with equal proportions of plants in. the 0 to 0.1 and 0.2 to $0.4 \mathrm{~mm}$ size ranges (Fig. 1 , Table 1). After $5 \mathrm{~d}$ inequality, measured by the Gini coefficient, was highest in the most dense populations (because there were very few largest plants 0.3 to $0.4 \mathrm{~mm}$ ) and lowest in the least dense ones. Subtle changes in equality and skewness of plant lengths occurred in the populations over the next $25 \mathrm{~d}$ (Fig. 1, Table 1).

After $5 \mathrm{~d}$ there was clearly a difference in 'subsequent' density between different density treatments, which confirmed the methodology (Fig. 2A). There was no significant interaction of density and time, and no significant effect of time on subsequent density (ANOVA Table 2). However, variation in density became large over time, and there may have been a trend towards higher mortality in higher density populations (Fig. 2A), which might have been discovered by increased replication or extension of the experimental run time.

No interaction was found between density and time for mean plant length, but there was a significant effect of density on mean plant size (ANOVA; Table 2), in that plants were on average larger in low density populations (Fig. 2B).

More strikingly, there was an interaction between time and density for mean dry weight per plant (ANOVA; Table 2). After 5 d plants in the lowest den-
Table 1. Fucus vesiculosus. Gini and skewness coefficients in propagule populations over $30 \mathrm{~d}$ after settlement at 3 densities in laboratory culture

\begin{tabular}{|c|c|c|c|}
\hline & $5 d$ & $14 \mathrm{~d}$ & $30 \mathrm{~d}$ \\
\hline \multicolumn{4}{|l|}{ Gini coefficient } \\
\hline High density & $0.213^{\mathrm{d}}$ & $0.261^{*}$ & $0241^{c}$ \\
\hline Medium density & 0.189 & $0.246^{\circ}$ & $0.179^{\circ}$ \\
\hline Low density & 0.176 & $0.192^{b}$ & 0.199 \\
\hline \multicolumn{4}{|l|}{ Skewness } \\
\hline High density & -0.020 & $-0.168^{e}$ & $-0.186^{c, 6}$ \\
\hline Medium density & -0.229 & $-0.314^{e}$ & $-0.277^{c}$ \\
\hline Low density & $-0.786^{d}$ & $-0.419^{\mathrm{f}}$ & $-0.505^{c e}$ \\
\hline \multicolumn{4}{|c|}{ avery few largest plants have great influence } \\
\hline \multicolumn{4}{|c|}{ 'Very few smallest plants have great influence } \\
\hline \multicolumn{4}{|c|}{${ }^{C}$ Removal of smallest plants (mortality?) } \\
\hline \multicolumn{4}{|c|}{ dMajority of plants in 2 largest size classes } \\
\hline \multicolumn{4}{|c|}{ "Majority of plants have moved into higher size classes } \\
\hline \multicolumn{4}{|c|}{$\begin{array}{l}\text { 'Plants represented by d (above) now distributed more } \\
\text { evenly }\end{array}$} \\
\hline
\end{tabular}

sity populations were heavier than those in the highest density popuiations, and diltel 14 ând 30 d heavicr than those in both the other populations (ANOVA, Tukey test $_{i}$ Fig. 2C). During the experiment no difference in plant weight could be detected between plants grown at high and medium densities (ANOVA, Tukey test; Fig. 2C). While there was a significant increase in the weight of plants in the most and least dense populations between. Days 5 and 14, there was no detectable increase in the medium density populations (ANOVA, Tukey test, Fig. 2C).

Maximum plant length was calculated as a mean of the largest plant in each field of view. There was an interaction in the effect of time and density on maximum plant length (ANOVA; Table 2). While ANOVA
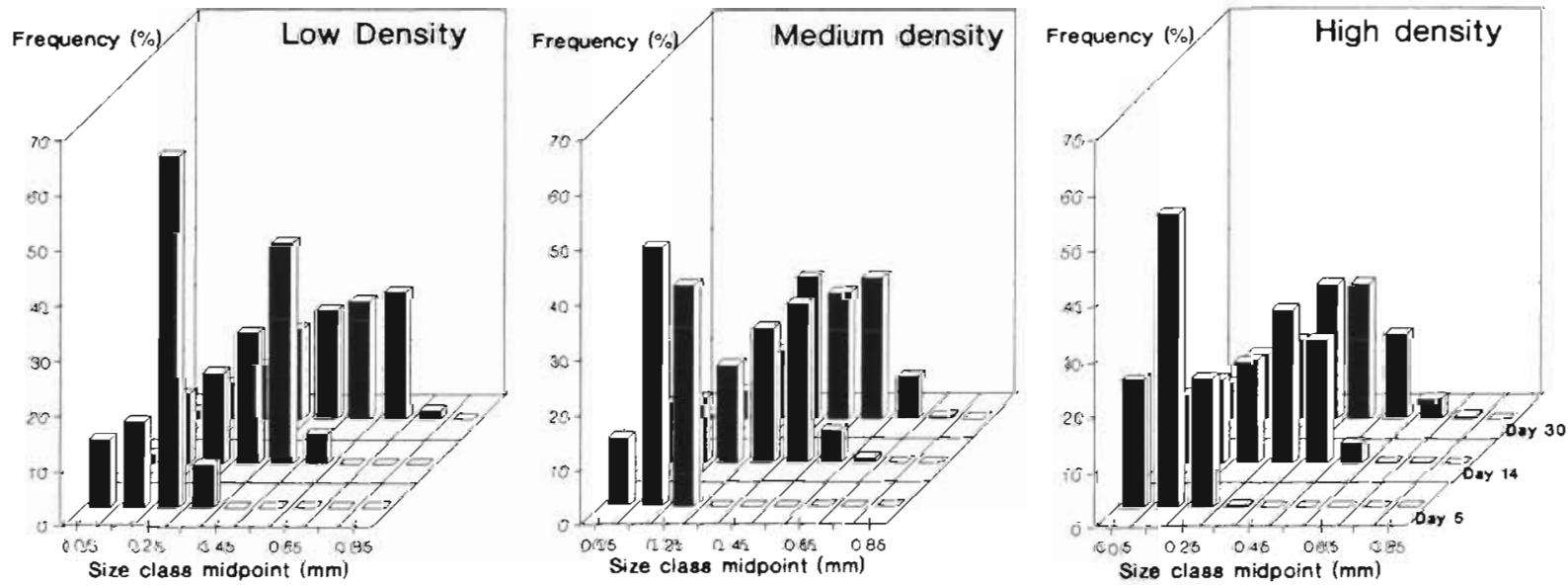

Fig. 1. Fucus vesiculosus. Size (length) frequency histograms of population structures of different density populations of propagules over $30 \mathrm{~d}$ post settlement in laboratory culture 

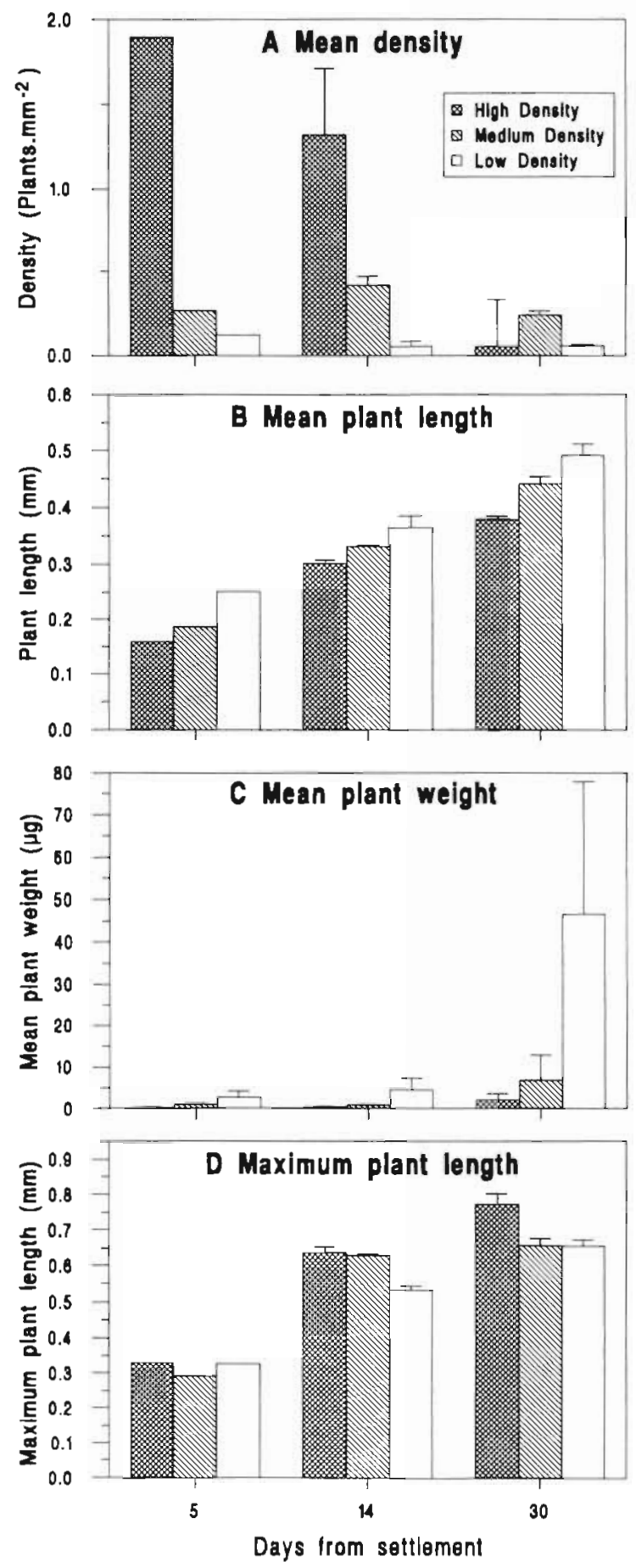

Fig. 2. Fucus vesiculosus. Mean ( \pm 1 SE) (A) density, (B) plant length, $(C)$ weight and (D) maximum plant length in 3 densities of propagules over $30 \mathrm{~d}$ post settlement in laboratory culture

revealed a difference between densities, Tukey tests were not sensitive enough to detect where. The trend suggested that the maximum plant length was higher in higher density populations than in lower density
Table 2. Fucus vesiculosus. ANOVA of density (square root transformed), mean plant length, mean plant dry weight and maximum plant length on the factors time, settlement density and replicate in populations of propagules grown in laboratory culture

\begin{tabular}{|c|c|c|c|c|}
\hline Factor & $\mathrm{df}$ & MS & $F$ & $\mathrm{p}$ \\
\hline \multicolumn{5}{|l|}{ Density } \\
\hline Time & 2 & 0.0398 & 1.07 & 0.425 \\
\hline Density & 2 & 2.7930 & 75.06 & 0.001 \\
\hline Replicate & 3 & 0.0262 & 0.84 & 0.483 \\
\hline Time $\times$ Density & 4 & 0.0372 & 1.20 & 0.336 \\
\hline Error & 24 & 0.0310 & & \\
\hline \multicolumn{5}{|l|}{ Mean plant length } \\
\hline Time & 2 & 0.171500 & 116.44 & $<0.001$ \\
\hline Density & 2 & 0.023794 & 16.16 & $<0.001$ \\
\hline Replicate & 3 & 0.003534 & 2.40 & 0.094 \\
\hline Time $x$ Density & 4 & 0.000796 & 0.54 & 0.707 \\
\hline Error & 24 & 0.001473 & & \\
\hline \multicolumn{5}{|c|}{ Mean plant dry weight } \\
\hline Time & 2 & 1142.8 & 10.04 & 0.001 \\
\hline Density & 2 & 1030.6 & 9.06 & 0.001 \\
\hline Replicate & 3 & 107.5 & 0.94 & 0.435 \\
\hline Time $\times$ Density & 4 & 688.7 & 6.05 & 0.002 \\
\hline Error & 24 & 113.8 & & \\
\hline \multicolumn{5}{|c|}{ Maximum plant length } \\
\hline Time & 2 & 0.463083 & 170.71 & $<0.001$ \\
\hline Density & 2 & 0.018029 & 6.65 & 0.005 \\
\hline Replicate & 3 & 0.001047 & 0.39 & 0.764 \\
\hline Time $\times$ Density & 4 & 0.007837 & 2.89 & 0.044 \\
\hline Error & 24 & 0.002713 & & \\
\hline
\end{tabular}

ones (Fig. 2D). Over time, all densities exhibited an increase in maximum plant length (ANOVA, Tukey; Fig. 2D).

\section{Field populations}

Frond length-frequency histograms (Fig. 3), skewness coefficients (Fig. 4) and plant density (Fig. 5A) illustrated that substantial changes had taken place in the population structure as a result of thinning. There was an increase in the proportion of plants in the smallest size class and a direct relationship of this with the degree of thinning (Fig. 3). Though this could simply have been an artifact (increased thinning resulting in proportionally greater importance placed on the first size class in frequency histograms), after $105 \mathrm{~d}$ the densities of populations had inverted so that the most thinned had the highest density and the unthinned the lowest density (Fig. 5A). During the first 28 d density increased in all the thinned populations, the greatest rate of macrorecruitment being found in the 2 most thinned populations and the least in the unthinned ones (Fig. 5A). The recruitment of small plants into thinned populations was reflected in the values of the 
skewness coefficient, and positive skewness developed more rapidly in more thinned populations, as small plants appeared in the most thinned populations (Fig. 4).

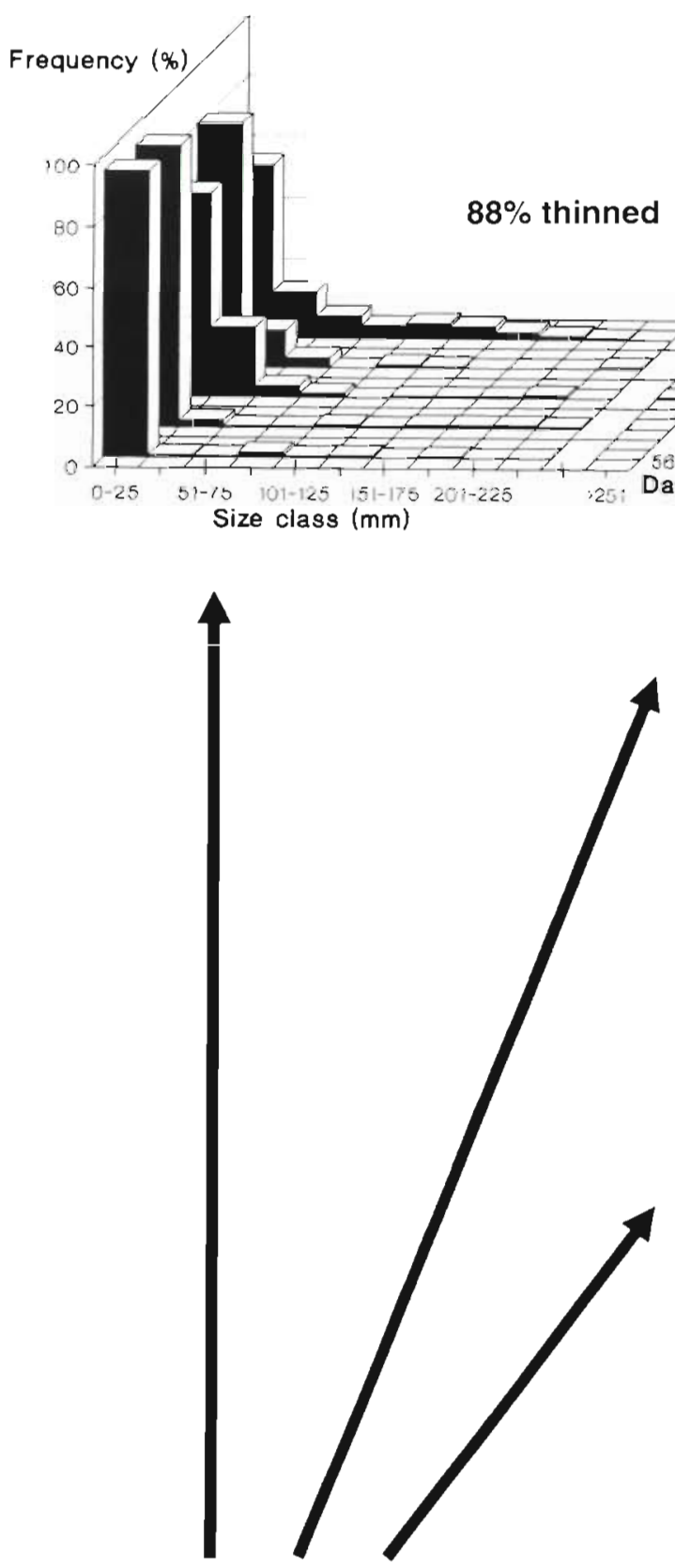

Frequency (\%)

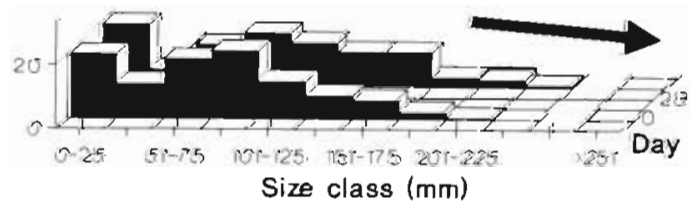

Thinning had a significant (ANOVA) effect on mean frond length (Table 3 ) in that small plants joining the populations depressed mean plant length. Thus there was an inverse relationship between thinning and mean frond weight. However, thinning had no effect on maximum frond length (the mean of the 5 largest plants, ANOVA; Table 3) and maximum frond length increased in all the manipulations over time.
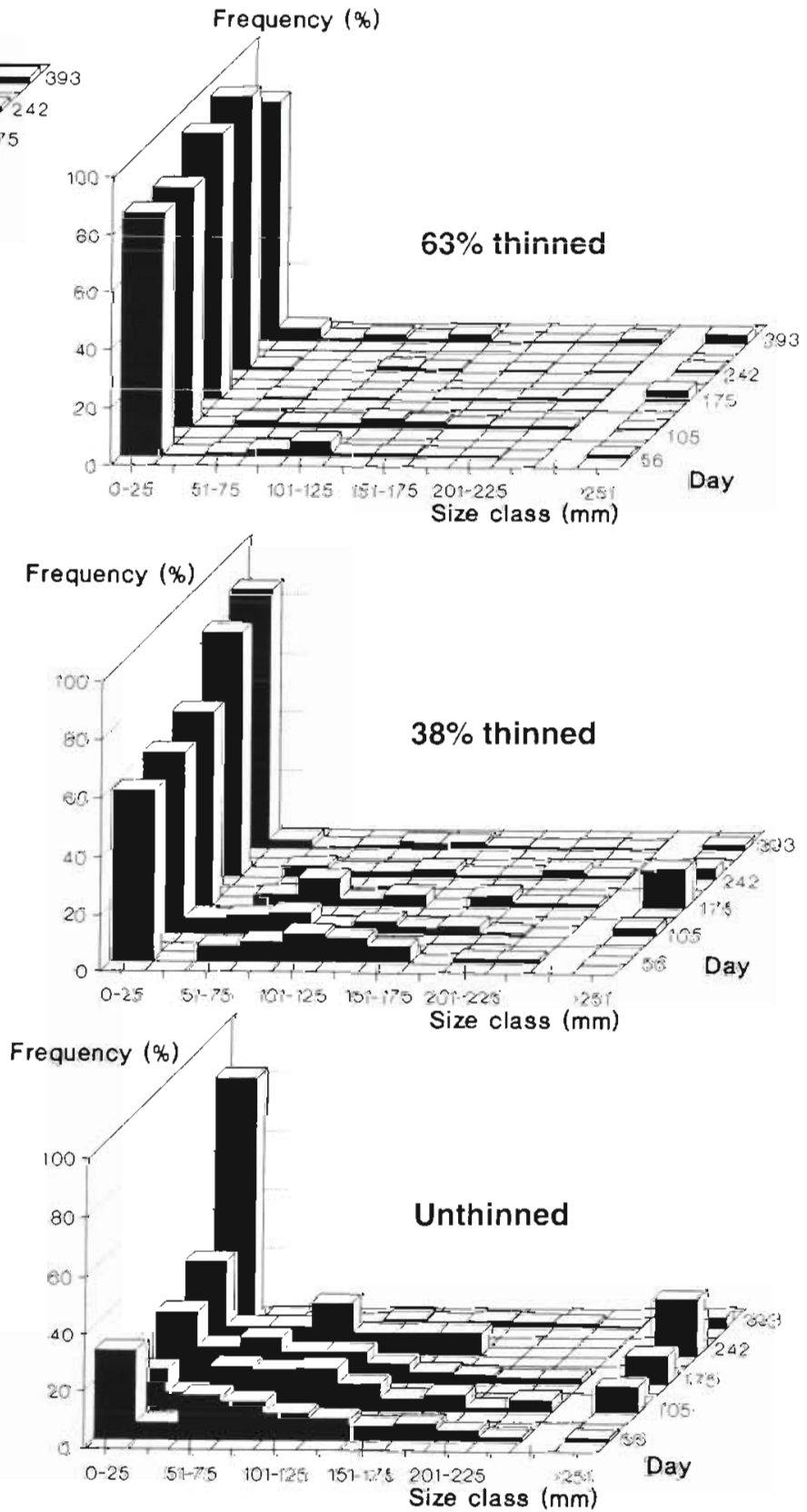

Fig. 3. Fucus vesiculosus. Size (length) frequency histograms of population structures of different density populations of artif1cially thinned stands over time 


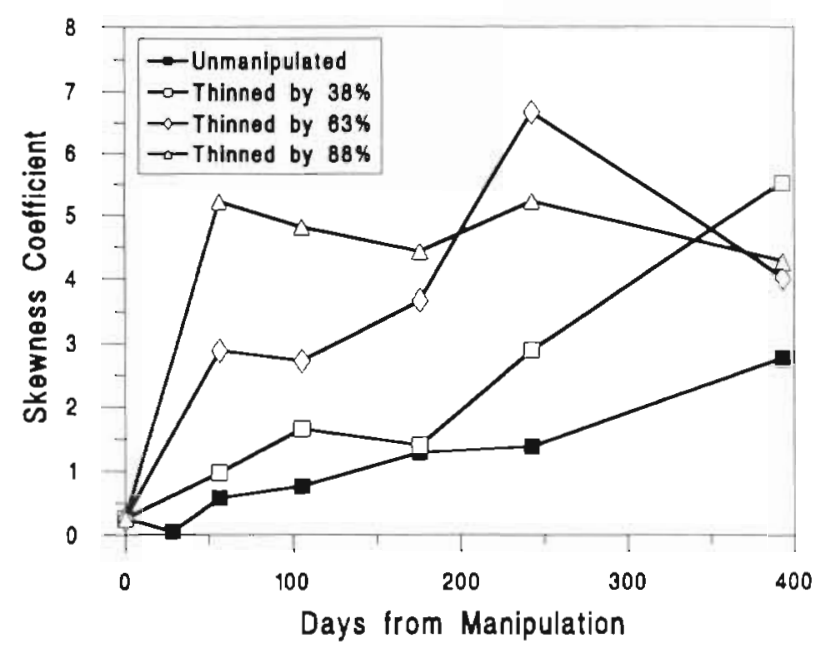

Fig. 4. Fucus vesiculosus. Skewness coefficient in different density populations of artificially thinned stands over time

Obviously mean frond density was initially lowest in the most thinned population and highest in the unmanipulated population (Fig, 5A). ANOVA revealed an interaction between thinning manipulation and time in their effect on subsequent density (Table 4). The greater the degree of thinning the larger the number of recruits (and thus density) became (Fig. 5A.). While the density of unthinned stands decreased throughout the experiment, stands thinned by $63 \%$ demonstrated no significant change in density, and stands thinned by $88 \%$ showed significant increases and decreases in density over time (ANOVA; Fig. 5A). Standing crops, different at the start, converged later in the experiment (ANOVA; Table 4, Fig. 5B).

ANOVA on arcsine transformed data revealed no difference between manipulations or interaction with time for reproductive allocation as percentage of biomass as reproductive tissue (Table 4, Fig. 3C), the only differences being over time (ANOVA, Tukey test).

Table 3. Fucus vesiculosus. ANOVA of mean and maximum plant length on the factor thinning treatment in experimentally thunned populations

\begin{tabular}{|rrrcc|}
\hline & df & MS & $F$ & $\mathrm{p}$ \\
\hline $\begin{array}{l}\text { Mean frond length } \\
\quad \text { Thinning manipulation }\end{array}$ & 3 & 4128 & 7.07 & 0.002 \\
$\quad$ & 20 & 584 & & \\
$\begin{array}{l}\text { Residual } \\
\text { Maximum frond length }\end{array}$ & & & & \\
$\quad \begin{array}{l}\text { Thinning manipulation } \\
\text { Residual }\end{array}$ & 3 & 6813 & 0.82 & 0.498 \\
\hline
\end{tabular}
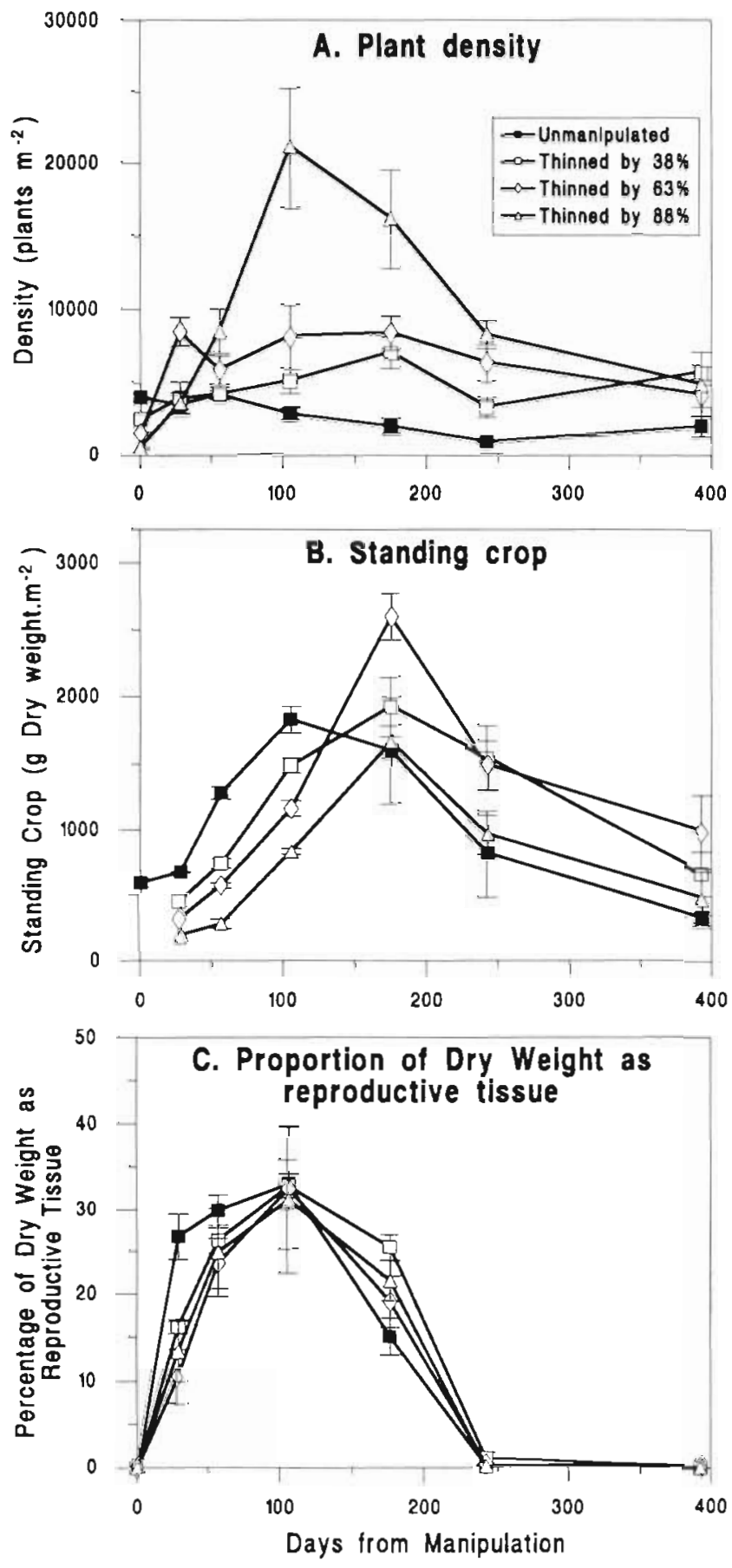

Fig. 5. Fucus vesıculosus. Mean $( \pm 1$ SE) (A.) plant density, (B) standing crop, and (C) proportion of dry weight as reproductive tissue in different density populations of artificially thinned stands over time

\section{DISCUSSION}

Theoretically, the first effects of intraspecific competition following propagule settlement are reduced growth rates at higher densities (e.g. Hutchings \& 
Table 4. Fucus vesiculosus. ANOVA of density, standing crop and percentage of biomass as reproductive tissue (arcsine transformed) on the factors time, thinning treatment and replicate in experimentally thinned populations

\begin{tabular}{|lrrrr|}
\hline & df & MS & $F$ & \multicolumn{1}{c|}{$\mathrm{p}$} \\
\hline Density & & & & \\
Time (A) & 5 & 2461677312 & 7.76 & $<0.001$ \\
Thinning (B) & 3 & 4670653440 & 14.72 & $<0.001$ \\
Replicate & 3 & 297437824 & 0.94 & 0.429 \\
A $\times$ B & 15 & 1067394880 & 3.36 & $<0.001$ \\
Error & 56 & 317379104 & & \\
Standing crop & & & & \\
Time (A) & 5 & 4477632 & 31.16 & $<0.001$ \\
Thinning (B) & 3 & 865590 & 6.02 & 0.001 \\
Replicate & 3 & 200145 & 1.39 & 0.254 \\
A $\times$ B & 15 & 371669 & 2.59 & 0.005 \\
Error & 56 & 143701 & & \\
\% dry weight as reproductive tissue & & \\
Timit (A) & 5 & 0.80548 & 85.20 & $<0001$ \\
Density (B) & 3 & 0.01078 & 1.14 & 0.341 \\
Replicate & 3 & 0.01897 & 2.01 & 0.123 \\
A $\times$ B & 15 & 0.00768 & 0.81 & 0.660 \\
Error & 56 & 0.00945 & & \\
\hline
\end{tabular}

Budd 1981). Subsequently density dependent mortality (self-thinning) may occur. In the laboratory populations of newly settled zygotes increasing density did indeed result in smaller, less heavy plants. Similar results have been found in other fucoids (Ward 1982, Ang \& De Wreede 1992) and kelps (Black 1974). To monitor mean plant weight in macroscopic populations we may weigh individuals. In microscopic populations this is extremely difficult, and we may use the population weight/density to estimate mean plant weight. This can be problematic because as total weight is taken, mean plant weight can become highly dependent on density. However, in this experiment, no significant mean plant weight-density relationship was found, whereas the density-standing crop relationship was strong, so the measure seemed to be a valid one.

We found no significant evidence of density dependent mortality in our laboratory populations of Fucus vesiculosus, a response which has been found in other young fucoids (Ang \& De Wreede 1992) and kelps (Black 1974, Reed 1990a, Reed et al. 1991). Probably, the earliest signs of negative density dependence are reduced growth rates, and only at a later stage does mortality start to take a toll. Early growth differences are of fundamental importance to individual plants: the largest plants not only outcompete smaller ones, but are more likely to survive to reproduce.

Differential growth resulted in a hierarchy of plant sizes and a negative skew in plant sizes - more large plants and fewer small ones. Reports of negative skew- ness are uncommon in the literature; we reviewed 37 publications which included population structures of 32 seaweed species, and found that only $10 \%$ reported negative skewness. Negative skewness may result from mortality of small plants, but, while the degree of skewness was density dependent, mortality was not (there was no interaction of time and density) and we can only conclude that differential growth was the cause of this skewing. Kenkel (1988) suggested a 2phase process for intraspecific competition. The first is a '2-sided' scramble ('resource depletion') where plants compete proportionally for nutrients, the second ' 1 -sided' ('asymmetric competition') is where lange plants disproportionally preempt light. In our culture experiment the propagules were not closely packed or multi-layered, and shading of smaller plants should not have taken place at this early stage. In the field we have found maximum densities of 26.8 plants $\mathrm{cm}^{-2}$. similar to our medium density laboratory populations. In the laboratory nutrient limitation at the betweenplant scale is the most likely option - only filtered sea water was used and, with no water movement, propagules may have suffered hutrient depletion noar the slide surface. Furthermore, leftover cultures were kept for over a year under similar conditions with little size increase, but when we added enriched sea water the plants gained a new lease of life, elongating vigorously.

The experimental thinning of field populations generated even more surprises than that of the laboratory populations. The field experiment was conceived to test the effect of intraspecific competition (as mediated by density) on various population parameters. Drawing on theory we had fully expected to find that with density remaining constant more vigorous growth of remaining plants in thinned stands would result in a restoration of the balance between biomass and density - the 'law' of constant final yield. What we had not expected was that density would increase in the visible population to take account of the fall in biomass.

The population structure of Fucus vesiculosus was soon dominated by thousands of macrorecruits (sensu Ang 1991) when plants were thinned from the population. The number of macrorecruits was predominantly dependent on the degree of the initial thinning.

That increased thinning should ultimately increase the density is a somewhat paradoxical result, but it demonstrates an important mechanism in Fucus vesiculosus. There can be little doubt that a 'bank' of microscopic juveniles exists in this species (see Hoffmann \& Santelices 1991 for a review of algal 'seed' banks). Thinnings were carried out at least 2 mo before gamete release could have taken place in that season. and at least 4 mo since any plant in the area had repro- 
duced (Knight \& Parke 1950, pers. obs.). Under a full canopy an increase in macrorecruits took place by October 1991 which must have originated from an April release, suggesting a lag period of up to 6 mo between settlement and the appearance of plants. This contrasts with the findings of Knight \& Parke (1950), who cleared and burned areas and estimated that settled spores would be visible to the naked eye as germlings within a fortnight. The implication is clear - even a greatly thinned canopy retards the development of conspecific germlings considerably. For instance by extrapolation of the relationship between maximum post-thinning density and percentage of plants remaining after thinning, we estimate that about 26000 potential plants $\mathrm{m}^{-2}$ are available in the microscopic spore/germling bank, equivalent to $9.7 \%$ of the maximum density we recorded in the field for $F$. vesiculosus.

Seed banks are probably not confined to Fucus vesiculosus - (macro)recruitment stimulated by thinning or clearance has been reported in several fucoids. Knight \& Parke (1950) cleared areas throughout the year and found that season made no difference to the numbers of macrorecruits in $F$. vesiculosus or $F$. serratus despite the seasonal nature of reproduction in these species. In fact several authors have found enhanced recruitment under thinned fucoid canopies (Cousens 1985, Robertson 1987, Chapman 1989, 1990. Ang 1991, McCook \& Chapman 1991, Ang \& De Wreede 1992)

In some experiments, as here, degrees of thinning rather than total removal have been carried out (Black 1974, Chapman \& Goudey 1983, Reed 1987, 1990b, McCook \& Chapman 1991), although as Reed (1990b) points out, such experiments are rare in benthic marine algal studies.

Black (1974) found that growth rates of sporophytes in thinned stands of Egregia leavigata (Setchell) were significantly greater than in unthinned controls. Again it is not clear whether a sporophyte or gametophyte bank was present before thinning, though it was noted that most new plants (macrorecruits) grew up in cracks where they were protected from scouring. Survivorship was higher in lower density plots for the first 3 mo. Chapman \& Goudey (1983), studying the annual brown alga Leathesia difformis (L.) Aresch., found that death rates were between 2 and 8 times higher in control plots than thinned areas, and crowding was the most important determinant of mortality rates. Reed (1987) found that artificial thinning significantly increased sporophyll biomass in Macrocystis pyrifera (L.) C.Ag. In the most complete treatment of artificial thinning of natural populations Reed (1990b) thinned a population of the subtidal kelp Pterygophora californica Ruprecht to 4 different densities using tagged individuals to follow various population parameters. He found that plants at low density generally outperformed those at high density in terms of growth and reproductive tissue allocation, and that greater recruitment took place under a low density canopy. However Reed (1990b) found no density dependent mortality and a distinct seasonal nature to density effects because of the deciduous nature of $P$. californica.

In Fucus vesiculosus the small plants were responsible for considerably lowering the mean frond length of the population. However, the growth of the largest plants was unaffected by thinning. One might expect this if these plants are the competitive dominants, in which case they should not be influenced by asymmetrical competition (i.e. for light, Thomas \& Weiner 1989).

That thinning in Fucus vesiculosus stimulated growth from a zygote/germling bank indicated a hierarchy of exploitation in this species. Skewness increased with time in the unmanipulated population, and this is indicative of intraspecific competition (Harper 1977). Positive skewness is also a feature widely found in other seaweed populations. Seaweed populations are subjected to stochastic events such as storm damage (Rosenthal et al. 1974, Cowen et al. 1982, Dayton \& Tegner 1984, Dayton et al. 1984), and the resultant natural thinning may stimulate macrorecruitment which will result in large numbers of small plants entering a normally distributed population, making it skewed. Alternatively, continuing intraspecific competition may keep the majority of competitive weaklings small.

The disparities in standing crop and density which were created by artificial thinning were eventually equalized by macrorecruitment, growth and mortality as the populations were stabilized by the carrying capacity of the niche. Probably self-thinning acted to reduce the density of the most thinned stands later in the experiment. There was an increase in standing crop up to the period of reproduction, after which it decreased. This was not surprising as up to $30 \%$ of the standing crop can be reproductive tissue, and necrosis of receptacles occurs after gametogenesis.

Terrestrial studies have shown that lower densities generally give a greater output per plant in reproductive terms (Clements et al. 1929, Hogdson \& Blackman 1957). However, in seaweeds, the effects of density on reproduction are less clear. For instance in our study we detected no influence of density on the reproductive output of Fucus vesiculosus, and similar conclusions were drawn by Ang \& De Wreede (1992) for their $F$ distichus populations. No difference in the proportion of dry weight as reproductive tissue was found. There are few studies which have concentrated on the importance of density on reproductive potential in seaweeds and those which have are contradictory. How- 
ever Reed $(1987,1990$ b) has demonstrated that plants of 2 kelp species, Macrocystis pyrifera and Pterygophora californica respectively, maintained greater per capita reproductive potential in lower density stands.

The current realisation that germing or spore banks occur in seaweeds has far reaching ecological and evolutionary implications. Much of the theoretical basis for population dynamics has come from the study of artificial populations of glasshouse plants or planted forest trees. Now marine ecologists are finding similar mechanisms in seaweeds. Density dependent growth does take place in Fucus vesiculosus, and if the prevalence of positively skewed populations is indicative of intraspecific competition, then most seaweed populations undergo this stress. There are however many variables which affect natural seaweed populations. In our study nutrients limited the growth of germlings in the laboratory producing a scramble for resources. However, on the shore populations of larger plants were light-limited, and neighbours were harmful. The result was '1-sided' ('asymmetric') competition where larqer plants won. However, larger plants may be more susceptible to stochastic events such as wave damage, and there is always the potential for germling bank residents to spring to life once more. A seed bank strategy may be the only option losers have to stay in the game, and it gives those individuals a small chance of scoring the goal of reproduction. However, the factors which limit growth in microscopic populations are not yet fully understood either in the laboratory or on the shore, and the interaction between density, light and nutrients would make for some tantalizingly interesting future experiments.

Acknowledgements. We thank M. Mortimer, and many other people who made this study possible. B. MacGregor and T Han gave us much time-saving advice in culturing algae. Critical comments from $M$. Figueiredo and the anonymous reviewers improved the manuscript. This study is part of a Ph.D. thesis carried out at the University of Liverpool's Port Erin Marine Laboratory supported by a studentship for J.C.C. from The Natural Environmental Research Council, United Kingdom

\section{LITERATURE CITED}

Ang PO (1991) Natural dynamics of a Fucus distichus population: reproduction and recruitment. Mar Ecol Prog Ser 78 : $71-85$

Ang PO. De Wreede RE (1992) Density dependence in a population of Fucus distichus, Mar Ecol Prog Ser 90:169-181

Begon M, Mortimer M (1986) Population ecology: a unified study of animals and plants. Blackwell, Oxford

Bendel RB, Higgins S.S, Teberg JE, Pyke DA (1989) Comparison of skewness coefficient, coefficient of variation, and Gini coefficient as inequality measures within populations. Oecologia 78:394-400
Black R (1974) Some biological interactıons affecting intertidal populations of the kelp Egregia laevigata. Mar Biol 28:189-198

Chapman ARO (1986) Population and community ecology of seaweeds. Adv mar Biol 23:1-161

Chapman ARO (1989) Abundance of Fucus spiralis and ephemeral seaweeds in a high eulittoral zone: effects of grazers, canopy and substratum type. Mar Biol 102: $565-572$

Chapman ARO (1990) Effects of grazing, canopy cover and substratum type on the abundances of common species of seaweeds inhabiting littoral fringe tide pools. Botanica Mar 33:319-326

Chapman ARO, Goudey CL (1983) Demographic study of the macrothallus of Leathesia difformis (Phaeophyta) in Nova Scotia. Can J Bot 61:319-323

Clements FE, Weaver JE, Hanson HC (1929) Competition in cultivated seedling survival. Carnegie Inst Washington Publ 398:202-233

Cousens R (1985) Frond size distributions and the effects of the algal canopy on the behavior of Ascophyllum nodosum. (L.) Le Jolis. J Exp Mar Biol Ecol 92:231-249

Cousens R (1986) Quantitative reproduction and reproductive effort by stands of the brown alga Ascophyllum nodosum (L.) Le Jolis in South-eastern Canada. Estuar Coast Shelf Sci 22:495-507

Cowen RK, Agegian CR, Foster MS (1982) The maintenance of community structure in a centisal Califôninia giant kelp forest. J Exp Mar Biol Ecol 64:189-201

Dayton PK, Currie V. Gerrodette $T$, Keller BD, Rosenthal R, Tresca DV (1984) Patch dynamics and stability of some California kelp communities. Ecol Monogr 54:253-289

Dayton PK, Tegner MJ (1984) Catastrophic storms, El Niño, and patch stability in a southern California kelp community. Science 224:283-285

Dixon PM, Weiner J, Mitchell-Olds T, Woodley R (1987) Bootstrapping the Gini coefficjent of inequality. Ecology 68 : $1548-1551$

Druehl LD, Breen PA (1986) Some ecological effects of harvesting Macrocystis integrifolia. Botanica Mar 29: $97-103$

Gerard VA, Mann KH (1979) Growth and production of Laminaria longicruris (Phaeophyta) populations exposed to different intensities of water movement. J Phycol 15:33-41

Harper JL (1977) Population biology of plants. Academic Press, London

Hay ME (1981) The functional morphology of turf forming seaweeds: persistence in stressful habitats. Ecology 62 : $739-750$

Hicks CR (1982) Fundamental concepts in the design of experiments. Holt Rinehart and Winston, New York

Hodgson GL, Blackman GE (1957) An analysis of the influence of plant density on the growth of Vicia faba. Part 1 The influence of density on the pattern of development. J Exp Bot 7:147-165

Hoffmann. AJ, Santelices B (1991) Banks of algal microscopic forms: hypotheses on their functioning and comparisons with seed banks. Mar Ecol Prog Ser 79:185-194

Hutchings MJ, Budd CSJ (1981) Plant competition and its course through time. BioSci 31:640-645

Hruby T, Norton TA (1979) Algal colonization on rocky shores in the Firth of Clyde. J Ecol 67:65-77

Hurlbert SH (1984) Pseudoreplication and the design of ecological field experiments. Ecol Monogr 54:187-211

Hurtado-Ponce AQ (1990) Vertical rope cultivation of Gracilaria (Rhodophyta) using vegetative fragments. Bolanica Mar 33:44:7-481 
Kenkel NC (1988) Pattern of self-thinning in Jack Pine: testing the random mortality hypothesis. Ecology 69: 1017-1024

Keser M, Larson BR (1984) Colonization and growth dynamics of three species of Fucus. Mar Ecol Prog Ser 15:125-134

Keser M, Vadas RL, Larson BR (1981) Regrowth of Ascophyllum nodosum and Fucus vesiculosus under various harvesting regimes in Maine, USA. Botanica Mar 24 : $29-38$

Kirkman $H$ (1981) The first year in the life history and the survival of the juvenile marine macrophyte Ecklonia radiata. J Exp Mar Biol Ecol 55:243-254

Knight M, Parke M (1950) A biological study of Fucus vesiculosus L. and Fucus serratus L. J Mar Biol Ass UK 29:439-514

Lubchenco J (1983) Littorina and Fucus: effects of herbivores, substratum heterogeneity, and plant escapes during succession. Ecology 64:1116-1123

McCook LJ, Chapman ARO (1991) Community succession following massive ice-scour on an exposed rocky shore effects of Fucus canopy algae and of mussels during late succession. J Exp Mar Biol Ecol 154:137-169

Reed DC (1987) Factors affecting the production of sporophylls in the giant kelp Macrocystis pyrifera (L.) C.Ag. J Exp Mar Biol Ecol 113:61-69

Reed DC (1990a) The effects of variable settlement and early competition on patterns of kelp recruitment. Ecology 71 : $776-787$

Reed DC (1990b) An experimental evaluation of density dependence in a subtidal algal population. Ecology 71 $2286-2296$

Reed DC, Neushul M, Ebeling AW (1991) Role of settlement density on gametophyte growth and reproduction in the kelps Pterygophora californica and Macrocystis pyrifera (Phaeophyceae). J Phycol 27:361-366

Robertson BL (1987) Reproductive ecology and canopy structure of Fucus sprialis L. Botanica Mar 30:475-482

Rosenthal RJ, Clarke WD, Dayton PK (1974) Ecology and natural history of a stand of giant kelp, Macrocystis pyrifera, off Del Mar, California. Fish Bull US 72:670-684

Santelices B, Ojeda FP (1984a) Effects of canopy removal on the understory algal community structure of coastal forests of Macrocystis pyrifera from southern South America. Mar Ecol Prog Ser 14:165-173

This article was submitted to the editor
Santelices B, Ojeda FP (1984b) Population dynamics of coastal forests of Macrocystis pyrifera in Puerto Toro, Isla Navarino, Southern Chile. Mar Ecol Prog Ser 14:175-183

Schiel DR (1985) Growth, survival and reproduction of two species of marine algae at different densities in natural stands. J Ecol 73:199-217

Schiel DR, Choat JH (1980) Effects of density on monospecific stands of marine algae. Nature 285:324-326

Schonbeck M, Norton TA (1978) Factors controlling the upper limits of fucoid algae on the shore. J Exp Mar Biol Ecol 31: 303-313

Thom RM (1983) Spatial and temporal patterns in Fucus distichus ssp. edentatus (de la Pyl.) Pow. (Phaeophyceae: Fucales) in Central Puget Sound. Botanica Mar 26 $471-486$

Thomas SC, Weiner J (1989) Including competitive asymmetry in measures of local interference in plant populations. Oecologia 80:349-355

Vadas RL, Johnson S, Norton TA (1992) Recruitment and mortality of early post-settlement stages of benthic algae. Br Phycol J 27:331-351

Vadas RL, Miller SL, Bolis CM, Bacon L, Wright W (1982) Population dynamics of Ascophyllum nodosum: factors influencing recruitment and germlings. In: Abstract, Proc Int Phycol Congr, Memorial University, St Johns, Newfoundland, Canada, p 51

Vadas RL, Wright WA, Miller SL (1990) Recruitment of Ascophyllum nodosum: wave action as a source of mortality. Mar Ecol Prog Ser 61:263-272

Ward E (1982) The effects of density of spore settlement on the initial growth and yield of marine algae. Honours project, Botany Department, University of Glasgow

Weiner J, Solbrig OT (1984) The meaning and measurement of size hierarchies in plant populations. Oecologia 61 $334-336$

Westermeier R, Möller P (1990) Population dynamics of Macrocystis pyrifera (L.) C. Agardh in the rocky intertidal of southern Chile. Botanica Mar 33:363-367

Yoshida T (1972) Relations between the density of individuals and the final yield in cultivated Porphyra. Bull Tohoku Reg Fish Res Lab 32:89-94

Zar JH (1984) Biostatistical analysis. Prentice-Hall International, London

Manuscript first received: December 19, 1994

Revised version accepted: September 21, 1995 